\title{
Bimetallic overlayer catalysts with high selectivity and reactivity for furfural hydrogenation
}

Chen Zhang, Qinghua Lai, Joseph H. Holles*

\author{
Department of Chemical Engineering \\ University of Wyoming
}

1000 E. University Ave.

Laramie, WY - 82071

* To whom correspondence should be addressed
jholles@ uwyo.edu
(307) 766-6772
Fax: (307) 766-2221

(C) 2016. This manuscript version is made available under the Elsevier user license http://www.elsevier.com/open-access/userlicense/1.0/ 


\begin{abstract}
:
Silica-supported platinum overlayer on nickel ( $\mathrm{Ni} @ \mathrm{Pt})$ or copper $(\mathrm{Cu} @ \mathrm{Pt})$ catalysts were synthesized and tested for furfural hydrogenation. $\mathrm{H}_{2}$ chemisorption and an ethylene hydrogenation descriptor showed weakened $\mathrm{H}_{2}$ binding strength of both overlayer catalysts compared to pure Pt, consistent with literature predictions. Cu@Pt showed higher turnover frequencies of furfural hydrogenation compared to pure Pt and pure $\mathrm{Cu}$. This improved reactivity is likely due to fewer Pt sites being blocked by strong hydrogen adsorption as a result of decreased $\mathrm{H}_{2}$ binding strength of Pt overlayer compared to pure Pt.
\end{abstract}

\title{
Keywords:
}

Furfural hydrogenation

Adsorption

Bimetallic

Overlayer

Platinum 


\section{Introduction:}

The growing demand for energy resources has stimulated extensive research on converting biomass into transportation fuels and valuable chemicals to alleviate the excessive consumption of fossil fuels. Derived from non-edible lignocellulosic biomass, furfural is currently considered as one of the most important biomass-derived chemicals that are available in large volume and high versatility $[1,2]$. Hydrogenation of furfural using heterogeneous catalysts has been widely studied as an important transformation of furfural into value-added products [2]. Furfuryl alcohol is the most common hydrogenation product of furfural, with $62 \%$ of furfural produced being transformed into furfuryl alcohol [3]. Furfuryl alcohol has been found to be useful in the manufacture of many products [3, 4], including resins, anti-corrosion plastics, and membranes.

Bimetallic overlayer catalysts with a pseudomorphic metal overlayer atop a different bulk metal have been shown to possess unique properties. Computational studies have predicted that the overlayer catalysts would exhibit decreased d-band center energy and thereby reduced $\underline{\mathrm{H}}_{2}$ adsorption strength $[5,6]$. Previous fuel cell and aqueous phase reforming studies proposed that strongly adsorbed $\mathrm{H}_{2}$ or $\mathrm{CO}$ would block Pt active sites and inhibit Pt reactivity [7, 8]. It is therefore hypothesized that Pt catalytic reactivity will be improved if the adsorption strength of $\mathrm{H}_{2}$ and $\mathrm{CO}$ on $\mathrm{Pt}$ is decreased. Such proposal was corroborated by previous glycerol hydrodeoxygenation study, as the Pt overlayer atop $\mathrm{Ni}$, Co or Ir showed higher hydrocarbon production reactivity compared to pure $\mathrm{Pt}[9,10]$. This enhancement was ascribed to the weaker adsorption strength of overlaying Pt compared to pure Pt, releasing Pt active sites from strongly adsorbed $\mathrm{H}_{2}$ or $\mathrm{CO}$, and increasing reactivity of Pt in reactions where an excessive amount of $\mathrm{H}_{2}$ (or $\mathrm{CO}$ ) was present. It was also reported that in furfural hydrogenation, intermediate hydrogen coverage on $\mathrm{Pd}(111)$ surface is likely to exhibit a lower energy barrier compared to higher hydrogen coverage, and typical reactor operations tend to induce high hydrogen coverage [11]. Accordingly, it is proposed that Pt reactivity of furfural hydrogenation could also be improved compared to pure $\mathrm{Pt}$ if $\mathrm{H}_{2}$ 
adsorption strength is decreased. Herein silica-supported Ni@Pt and Cu@Pt (core@shell) overlayer catalysts were synthesized to investigate the effect of reduced $\mathrm{H}_{2}$ adsorption strength of overlayer catalysts on furfural hydrogenation reactivity.

\section{Experimental:}

\subsection{Catalyst Synthesis}

Monometallic parent catalysts (pure $\mathrm{Ni}$, pure $\mathrm{Cu}$, and pure $\mathrm{Pt}$ ) and non-structured bimetallic alloy catalysts (Ni-Pt and $\mathrm{Cu}-\mathrm{Pt}$ ) were synthesized using incipient wetness impregnation of silica gel (SigmaAldrich, Davisil Grade 633) (See the Supplementary Information for more details). Two pure Pt catalysts were synthesized: 5 wt.\% Pt sample was used for hydrogen adsorption studies $\left(\mathrm{H}_{2}\right.$ chemisorption and ethylene hydrogenation), and 0.5 wt.\% Pt was used for furfural hydrogenation reactions so that the number of Pt active sites per gram of catalyst was similar to Ni- and $\mathrm{Cu}$-based catalysts. $\mathrm{Ni} @ \mathrm{Pt}$ and $\mathrm{Cu} @ \mathrm{Pt}$ overlayer catalysts were prepared using the directed deposition technique $[9,12]$. This technique was adapted from the refilling method developed by Womes et al. [13] which was originally used for synthesizing Pt catalysts with controlled Pt particle sizes. Detailed procedures could be found in the Supplementary Information.

\subsection{Sample Characterization Studies}

Metal loadings were obtained through inductively coupled plasma atomic emission spectroscopy (ICP-AES) performed in the Geochemistry Analytical Laboratory, University of Wyoming. Transmission electron microscopy (TEM) images were recorded with JEOL JEM-2100F high-resolution transmission electron microscopes. Hydrogen chemisorption studies were conducted using a Micromeritics ASAP 2020. Hydrogen isotherms were gathered at temperatures between $100^{\circ} \mathrm{C}$ and $350^{\circ} \mathrm{C}$ at pressures ranging from 1 mTorr to 900 Torr. Heats of $\mathrm{H}_{2}$ adsorption were calculated using the Clausius-Clapeyron equation for the ideal gas [14]. Ethylene hydrogenation reactivity was studied as a descriptor reaction. The details of this reaction were described in the Supplementary Information. 


\subsection{Activity Testing:}

Prior to the reaction, all catalysts were reduced at $400^{\circ} \mathrm{C}$ for $3 \mathrm{~h}$. Furfural hydrogenation reactions were performed in a $500 \mathrm{~mL}$ Parr 4575 bench top stainless steel reactor. The reactor was loaded with the isopropanol solvent (100 g), furfural (5 g), and the catalyst (100 mg to $300 \mathrm{mg})$. The sealed vessel was purged with hydrogen three times to remove air before the vessel was pressurized with hydrogen to 100 psi. The vessel was then heated to $250^{\circ} \mathrm{C}$ using a $3^{\circ} \mathrm{C} / \mathrm{min}$ ramp, with the stirring speed of $600 \mathrm{RPM}$. After the ramp, the reaction was allowed to proceed for $10 \mathrm{~h}$. GC-MS equipped with an Agilent J\&W DB624 column was used to analyze the liquid sample.

\section{Results and discussion}

\subsection{Catalyst Characterization}

The elemental analysis of each catalyst obtained from ICP is reported in Table 1. Metal dispersions determined by total $\mathrm{H}_{2}$ chemisorption of each catalyst at $35^{\circ} \mathrm{C}$ are also shown in Table 1 (no distinction was made as to the metal type). Pt overlayer coverages were calculated assuming all platinum in overlayer catalysts is on the surface (100\% platinum dispersion). Both $\mathrm{Ni@Pt} \mathrm{and} \mathrm{Cu} @ \mathrm{Pt}$ showed high overlayer coverage (>60\%). TEM images of $\mathrm{Ni@Pt} \mathrm{overlayer} \mathrm{catalyst} \mathrm{could} \mathrm{be} \mathrm{found} \mathrm{in} \mathrm{the}$ Supplementary Information as Figure S1. The distribution of Pt in Ni@Pt overlayer catalyst was investigated in high-angle annular dark field scanning transmission electron microscopy (HAADFSTEM) imaging and energy-dispersive x-ray spectroscopy (EDX) mapping. As shown in Figure 1, Pt is

highly dispersed on the Ni parent particles without any sign of Pt agglomeration or Pt particle formation. This result is consistent with previous HAADF-STEM study on $\operatorname{Ir} @ \mathrm{Pt} / \mathrm{SiO}_{2}-\mathrm{Al}_{2} \underline{\mathrm{O}}_{3}$ synthesized by the same procedure, showing that the deposited Pt overlayer is more concentrated on the surface (or edge) than in the bulk [10]. 


\subsection{Adsorption studies:}

The heat of hydrogen adsorption determined using the Clausius-Clapeyron equation is shown in Table 2 (no distinction was made as to the metal type). Pure Pt showed the highest hydrogen heat of adsorption, while both $\mathrm{Ni} @ \mathrm{Pt}$ and $\mathrm{Cu} @ \mathrm{Pt}$ displayed reduced heats of adsorption compared to pure Pt. Computational studies predicted weakened adsorption strength of Pt overlayer atop $\mathrm{Ni}$ or $\mathrm{Cu}$ compared to the Pt-only catalyst, due to a decrease in the d-band center energy of overlaying Pt [15]. Decreased heats of $\mathrm{H}_{2}$ adsorption for both overlayer catalysts observed in this study are consistent with literature predictions.

The ethylene hydrogenation reactivity has been correlated with hydrogen adsorption strength at low hydrogen coverage $[9,12,16]$. Although it has been proposed that hydrogen could block catalytic $\underline{\text { active sites in other reactions }[7,8] \text {, no evidence was observed showing that such an inhibitive effect of }}$ strong hydrogen binding is also present in ethylene hydrogenation. Therefore, ethylene hydrogenation reactivity is used as a descriptor for hydrogen adsorption strength and hydrogen surface coverage. Turnover frequencies (TOF) of ethylene hydrogenation over all catalysts are shown in Table 2. All $\underline{\text { turnover frequencies for monometallic catalysts (pure } \mathrm{Ni}, \mathrm{Cu} \text {, and } \mathrm{Pt} \text { ) and bimetallic alloys (Ni-Pt and } \mathrm{Cu}-}$ $\underline{\text { Pt) were calculated based on metal active sites determined with metal loading and hydrogen dispersions }}$ (Table 1). Because pure $\mathrm{Pt}$ was much more active in ethylene hydrogenation than pure Ni or pure $\mathrm{Cu}$, it is reasonable to attribute all the reactivity of overlayer catalysts to the Pt overlayer present. For overlayer samples, turnover frequencies were normalized using Pt loadings determined from elemental analysis and assuming $100 \%$ of dispersion of the Pt. Because the reactivity of pure $\mathrm{Cu}, \mathrm{Cu} @ \mathrm{Pt}$ and $\mathrm{Cu}-\mathrm{Pt}$ was below detection at $273 \mathrm{~K}, \mathrm{TOF}$ at $313 \mathrm{~K}$ for pure $\mathrm{Cu}, \mathrm{Cu} @ \mathrm{Pt}$ and $\mathrm{Cu}-\mathrm{Pt}$ are presented in Table 2. Both Ni@Pt and $\mathrm{Cu} @$ Pt overlayer catalysts showed lower ethylene hydrogenation TOF than pure Pt. Previous studies have established a positive relationship between hydrogen adsorption strength and ethylene hydrogenation reactivity $[9,16]$. In this respect, this decreased TOF in ethylene hydrogenation of overlayer catalysts, as well as reduced heats of $\mathrm{H}_{2}$ adsorption from $\mathrm{H}_{2}$ chemisorption, indicated reduced $\mathrm{H}_{2}$ binding strength of 
$\mathrm{Ni@Pt} \mathrm{and} \mathrm{Cu} @ \mathrm{Pt}$ compared to the pure Pt [5]. Non-structured alloy catalysts (Ni-Pt and Cu-Pt) showed different heats of $\mathrm{H}_{2}$ adsorption and ethylene hydrogenation reactivity compared to the corresponding overlayer catalyst. This demonstrates the intrinsic difference in structure and property between bimetallic alloys and overlayer catalysts.

\subsection{Furfural hydrogenation:}

The result of furfural hydrogenation at $250^{\circ} \mathrm{C}$ after $1.5 \mathrm{~h}$ of reaction is summarized in Table 3 . Turnover frequencies for furfural conversion of all catalysts in Table 3 were calculated based on the amount of total exposed metal sites determined from $\mathrm{H}_{2}$ chemisorption at $308 \mathrm{~K}$ (no effort was made to distinguish the reactivity of Pt sites and parent metal sites). Furfuryl alcohol, the desired product, was produced predominantly for most catalysts under the reaction condition (with exceptions being Ni@Pt and $\mathrm{Ni}-\mathrm{Pt}$ ), indicating that the hydrogenation of the $\mathrm{C}=\mathrm{O}$ double bond was the dominant reaction for most catalysts. Pure Ni and pure Pt showed higher selectivity toward furan than pure $\mathrm{Cu}$, indicating stronger decarbonylation reactivity of pure Ni and pure Pt. This is consistent with previous literature observations, reporting that pure $\mathrm{Ni}$ and pure $\mathrm{Pt}$ were more reactive in $\mathrm{C}-\mathrm{C}$ bond scission than pure $\mathrm{Cu}$ [17-20]. Pure $\mathrm{Cu}$ showed furfuryl alcohol selectivity of $94 \%$, which was similar to the $98 \%$ selectivity Sitthisa and Resasco obtained at $230^{\circ} \mathrm{C}$ with $10 \mathrm{wt} \% \mathrm{Cu} / \mathrm{SiO}_{2}[19]$.

Ni@Pt showed a higher TOF than pure Ni, but similar to pure Pt. Although the dispersion of

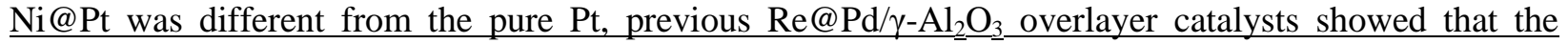
dispersion (or particle size) difference was not dominant in determining the overlayer adsorption strength and catalyst reactivity [21]. Therefore, it is probable that Pt sites in Ni@Pt were more reactive than Pt sites in pure Pt, because by normalizing TOF on the total number of sites, the inclusion of the less active Ni sites decreased the reported TOF. Cu@Pt displayed a higher TOF in furfural conversion than either pure Pt or pure $\mathrm{Cu}$. In order to separate out the specific reactivity of surface Pt sites in both overlayer 
catalysts, furfural conversion TOF of surface Pt sites of $\mathrm{Ni} @ \mathrm{Pt}$ and $\mathrm{Cu} @ \mathrm{Pt}$ were also calculated. This was done by subtracting the parent metal contribution from overall furfural conversion rates and normalizing remaining rates with the number of platinum atoms based on platinum overlayer coverages from Table 1 (details could be found in the Supplementary Information). A correlation of furfural conversion TOF of $\underline{\text { surface Pt sites of both overlayer catalysts and pure Pt vs. their hydrogen heat of adsorption is shown as }}$ Figure 2. It can been seen that as hydrogen adsorption strength decreased, furfural conversion TOF of

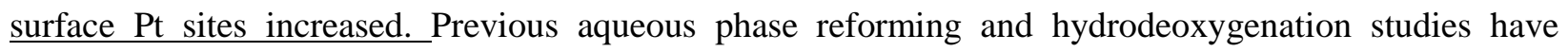
proposed that $\mathrm{H}_{2}$ would bind strongly to the Pt surface, resulting in a decrease in available catalytic active sites [7, 8, 22]. In this respect, weakened adsorption strength of $\mathrm{H}_{2}$ or $\mathrm{CO}$ on $\mathrm{Pt}$ sites could result in enhanced Pt reactivity. Density functional theory calculations also suggested that the furfural reaction rate would exhibit a maximum at intermediate hydrogen coverage [11]. Therefore, it is speculated that by reducing the adsorption strength of Pt active sites, Pt reactivity in furfural conversion could be improved. In this study, the correlation in Figure 2 corroborated this hypothesis. The reduction of $\mathrm{H}_{2}$ adsorption strength could release more Pt sites from the strongly adsorbed $\mathrm{H}_{2}$ (or $\mathrm{CO}$ ), so that reactivity of overlayer catalysts in furfural hydrogenation was enhanced from pure Pt.

Figure 3 shows the selectivity toward furfuryl alcohol as a function of reaction time. Detailed conversion and product selectivity for all catalysts can be found in the Supplementary Information (Figure S2-S8). Both $\mathrm{Cu}$ and $\mathrm{Cu} @ \mathrm{Pt}$ displayed high selectivity (>92\%) toward furfuryl alcohol throughout the experiment. Such high furfuryl alcohol selectivity of $\mathrm{Cu} @ \mathrm{Pt}$ demonstrated the promising potential of overlayer catalysts in catalytic reactions, especially considering the low platinum loading in $\mathrm{Cu} @ \mathrm{Pt}$ (around 0.05 wt.\%). Combined with the TOF enhancement as shown in Table 3 and Figure 2, both high reactivity and high selectivity were achieved at the same time with the $\mathrm{Cu} @ \mathrm{Pt}$ overlayer catalyst. As shown in Figure S4, Ni@Pt displayed lower furfuryl alcohol selectivity but higher furan selectivity than either pure Pt or pure Ni. Previous research has demonstrated the possibility of overlayer catalysts exhibiting properties that were beyond the pure components $[23,24]$. The behaviors of $\mathrm{Ni} @ \mathrm{Pt}$ for furfural 
hydrogenation also exhibited distinct selectivity but similar reactivity with overlayer catalysts compared to the pure metal components.

$\mathrm{Cu} @ \mathrm{Pt}$ showed selectivity toward furfuryl alcohol similar to pure $\mathrm{Cu}$ and higher than pure Pt. High furfuryl alcohol selectivity of $\mathrm{Cu} @ \mathrm{Pt}$ was an indication of increased furfuryl alcohol selectivity of the Pt overlayer compared to pure Pt, since the Pt overlayer coverage was above $60 \%$ in $\mathrm{Cu} @ \mathrm{Pt}$ as shown in Table 1. Density function theory (DFT) calculations showed that furfural adsorbed on the Pt and Pd surface through unsaturated $\mathrm{C}=\mathrm{O}$ and $\mathrm{C}=\mathrm{C}$ bonds, with the furan ring parallel to the surface [25], and such adsorption geometry was believed to facilitate decarbonylation reactions [26, 27]. Resasco et al. observed increased selectivity toward furfuryl alcohol when alloying $\mathrm{Pd}$ with $\mathrm{Cu}$, and such behavior was explained by the reduced d-band center energy and weaker binding strength, so that $\mathrm{C}=\mathrm{O}$ and $\mathrm{C}=\mathrm{C}$ bond affinity to the surface was weakened [26]. This conclusion likely also applies to the current study, as the adsorption strength was significantly reduced from pure Pt to $\mathrm{Cu} @ \mathrm{Pt}$ (from $51 \mathrm{~kJ} / \mathrm{mol}$ for $\mathrm{H}_{2}$ on $\mathrm{Pt}$ to 14 $\mathrm{kJ} / \mathrm{mol}$ for $\mathrm{H}_{2}$ on $\mathrm{Cu} @ \mathrm{Pt}$ ). With weakened adsorption on $\mathrm{Cu} @ \mathrm{Pt}$, it is speculated that binding strength of $\mathrm{C}=\mathrm{C}$ and $\mathrm{C}=\mathrm{O}$ to the surface was also reduced, so that the interaction with the electronegative oxygen atom from the furfural molecule became more dominant, leading to increased reactivity of hydrogenation reactions [28].

\section{4: Conclusions}

Silica-supported bimetallic Ni@Pt and Cu@Pt overlayer catalysts were synthesized using the directed deposition technique. $\mathrm{H}_{2}$ chemisorption and ethylene hydrogenation reactivity indicated that $\mathrm{H}_{2}$ adsorption strength of overlaying Pt in $\mathrm{Ni@Pt} \mathrm{and} \mathrm{Cu} @ \mathrm{Pt}$ was reduced from the pure Pt, in agreement with literature predictions. Both overlayer catalysts showed higher reactivity in furfural conversion compared to their parent metals. This enhancement could be ascribed to the reduced binding strength of $\mathrm{H}_{2}$ on $\mathrm{Pt}$ surface, resulting in fewer $\mathrm{Pt}$ sites blocked by the strong $\mathrm{H}_{2}$ adsorption and increased $\mathrm{Pt}$ reactivity. Also, high furfuryl alcohol selectivity was obtained with the $\mathrm{Cu} @ \mathrm{Pt}$ overlayer catalyst as well 
as higher reactivity. This suggests the advantage of $\mathrm{Pt}$ overlayer catalysts to improve the reactivity without sacrificing the selectivity.

\section{Acknowledgements}

The authors would like to acknowledge funding support provided by National Science Foundation, Chemical, Bioengineering, Environmental and Transport Systems [CBET-0933017]. C. Zhang acknowledges support from the University of Wyoming through an Energy GA award. The authors gratefully thank Dr. Roy Geiss for his help with TEM measurements. 


\section{References:}

[1] P. Gallezot, Chem. Soc. Rev. 41 (2012) 1538-1558.

[2] Y. Nakagawa, M. Tamura, K. Tomishige, ACS Catal. 3 (2013) 2655-2668.

[3] A. Mandalika, L. Qin, T.K. Sato, T. Runge, Green Chem. 16 (2014) 2480-2489.

[4] W.J. McKillip, G. Collin, H. Höke, K.J. Zeitsch, Ullmann's encyclopedia of industrial chemistry (2000).

[5] J.G. Chen, C.A. Menning, M.B. Zellner, Surf. Sci. Rep. 63 (2008) 201-254.

[6] W.T. Yu, M.D. Porosoff, J.G.G. Chen, Chem. Rev. 112 (2012) 5780-5817.

[7] G.W. Huber, J.W. Shabaker, S.T. Evans, J.A. Dumesic, Appl. Catal., B 62 (2006) 226-235.

[8] A. Gross, Top. Catal. 37 (2006) 29-39.

[9] C. Zhang, Q. Lai, J.H. Holles, Catal. Sci. Technol. 6 (2016) 4632-4643.

[10] C. Zhang, Q. Lai, J.H. Holles, Appl. Catal., A 526 (2016) 113-125.

[11] S.G. Wang, V. Vorotnikov, D.G. Vlachos, ACS Catal. 5 (2015) 104-112.

[12] M.D. Skoglund, C.L. Jackson, K.J. McKim, H.J. Olson, S. Sabirzyanov, J.H. Holles, Appl. Catal., A 467 (2013) 355-362.

[13] M. Womes, T. Cholley, F. Le Peltier, S. Morin, B. Didillon, N. Szydlowski-Schildknecht, Appl. Catal., A 283 (2005) 9-22.

[14] M.P. Latusek, R.M. Heimerl, B.P. Spigarelli, J.H. Holles, Appl. Catal., A 358 (2009) 79-87.

[15] A. Ruban, B. Hammer, P. Stoltze, H.L. Skriver, J.K. Norskov, J. Mol. Catal. A: Chem. 115 (1997) 421-429.

[16] M.P. Latusek, B.P. Spigarelli, R.M. Heimerl, J.H. Holles, J. Catal. 263 (2009) 306-314.

[17] S. Bhogeswararao, D. Srinivas, J. Catal. 327 (2015) 65-77.

[18] B.F. Chen, F.B. Li, Z.J. Huang, G.Q. Yuan, Appl. Catal., A 500 (2015) 23-29.

[19] S. Sitthisa, D.E. Resasco, Catal. Lett. 141 (2011) 784-791.

[20] J. Kijenski, P. Winiarek, T. Paryjczak, A. Lewicki, A. Mikolajska, Appl. Catal., A 233 (2002) 171-182.

[21] M.D. Skoglund, J.H. Holles, Catal. Lett. 143 (2013) 966-974.

[22] Y.T. Kim, J.A. Dumesic, G.W. Huber, J. Catal. 304 (2013) 72-85.

[23] O. Skoplyak, M.A. Barteau, J.G. Chen, Chemsuschem 1 (2008) 524-526.

[24] A. Roudgar, A. Gross, J. Electroanal. Chem. 548 (2003) 121-130.

[25] B. Liu, L. Cheng, L. Curtiss, J. Greeley, Surf. Sci. 622 (2014) 51-59.

[26] S. Sitthisa, T. Pham, T. Prasomsri, T. Sooknoi, R.G. Mallinson, D.E. Resasco, J. Catal. 280 (2011)

17-27.

[27] S.H. Pang, J.W. Medlin, ACS Catal. 1 (2011) 1272-1283.

[28] S. Sitthisa, T. Sooknoi, Y.G. Ma, P.B. Balbuena, D.E. Resasco, J. Catal. 277 (2011) 1-13. 
Table 1. Metal loading of samples (no distinction was made as to the metal type for dispersion values).

\begin{tabular}{llcl}
\hline Sample & Result wt.\% & Dispersion \% & Calculated \% overlayer \\
\hline $\mathrm{Ni} / \mathrm{SiO}_{2}$ & $4.84(\mathrm{Ni})$ & 4.90 & 63 \\
$\mathrm{Ni} @ \mathrm{Pt}$ & $4.72(\mathrm{Ni})$ & 5.97 & \\
& $0.480(\mathrm{Pt})$ & & \\
$\mathrm{Ni}-\mathrm{Pt}$ & $5.04(\mathrm{Ni})$ & 15.0 & \\
& $0.287(\mathrm{Pt})$ & & \\
& & & \\
& $5.66(\mathrm{Cu})$ & 0.541 & \\
$\mathrm{Cu} / \mathrm{SiO}_{2}$ & $4.82(\mathrm{Cu})$ & 0.371 & \\
$\mathrm{Cu} @ \mathrm{Pt}$ & $0.0451(\mathrm{Pt})$ & & \\
& $5.03(\mathrm{Cu})$ & 0.510 & \\
$\mathrm{Cu}-\mathrm{Pt}$ & $0.100(\mathrm{Pt})$ & & \\
& & & \\
& $4.48(\mathrm{Pt})$ & 37.8 & \\
$\mathrm{Pt} / \mathrm{SiO}_{2}$ (adsorption) & $0.485(\mathrm{Pt})$ & 44.5 & \\
$\mathrm{Pt} / \mathrm{SiO}_{2}$ (reactivity) & & & \\
\hline
\end{tabular}

Table 2. Calculated heat of $\mathrm{H}_{2}$ adsorption using the Clausius-Clapeyron equation and the measured ethylene hydrogenation turnover frequency (TOF) at $273 \mathrm{~K}$.

\begin{tabular}{lll}
\hline Catalyst & Heat of $\mathrm{H}_{2}$ adsorption $\mathrm{kJ} / \mathrm{mol}$ & Measured ethylene hydrogenation $\mathrm{TOF} \mathrm{s}^{-1}$ \\
\hline $\mathrm{Ni} / \mathrm{SiO}_{2}$ & 41 & 0.00731 \\
$\mathrm{Ni} @ \mathrm{Pt}$ & 44 & 1.154 \\
$\mathrm{Ni}-\mathrm{Pt}$ & 49 & 0.0132 \\
& & \\
$\mathrm{Cu} / \mathrm{SiO}_{2}$ & 19 & $0.0250(313 \mathrm{~K})$ \\
$\mathrm{Cu} @ \mathrm{Pt}$ & 14 & $0.114(313 \mathrm{~K})$ \\
$\mathrm{Cu}-\mathrm{Pt}$ & 21 & $0.0812(313 \mathrm{~K})$ \\
& & \\
$\mathrm{Pt} / \mathrm{SiO}_{2}$ & 51 & 6.84 \\
\hline
\end{tabular}


Table 3. Turnover frequencies and selectivity values for furfural conversion at $1.5 \mathrm{~h}$.

\begin{tabular}{|c|c|c|c|c|c|c|}
\hline \multirow{2}{*}{ Catalyst } & \multirow{2}{*}{$\begin{array}{l}\text { Furfural } \\
\text { conversion }\end{array}$} & \multirow{2}{*}{ TOF $h^{-1}$} & \multicolumn{3}{|c|}{ Product selectivity mol \% } & \multirow{2}{*}{$\begin{array}{l}\text { Carbon } \\
\text { balance } \%\end{array}$} \\
\hline & & & Furfuryl alcohol & Furan & 2-Methylfuran & \\
\hline $\mathrm{Ni}$ & $9.6 \%$ & 564 & $78.9 \%$ & $19.6 \%$ & $1.4 \%$ & 88 \\
\hline $\mathrm{Ni@Pt}$ & $43.3 \%$ & 2297 & $38.5 \%$ & $60.8 \%$ & $0.6 \%$ & 109 \\
\hline $\mathrm{Ni}-\mathrm{Pt}$ & $44.1 \%$ & 912 & $46.4 \%$ & $53.0 \%$ & $0.6 \%$ & 86 \\
\hline $\mathrm{Cu}$ & $14.2 \%$ & 3859 & $94.4 \%$ & $4.4 \%$ & $1.1 \%$ & 116 \\
\hline $\mathrm{Cu} @ \mathrm{Pt}$ & $15.3 \%$ & 11015 & $90.5 \%$ & $8.1 \%$ & $1.3 \%$ & 102 \\
\hline $\mathrm{Cu}-\mathrm{Pt}$ & $16.4 \%$ & 4229 & $86.8 \%$ & $11.3 \%$ & $1.9 \%$ & 86 \\
\hline $\mathrm{Pt}$ & $12.5 \%$ & 2430 & $55.8 \%$ & $43.1 \%$ & $1.1 \%$ & 112 \\
\hline
\end{tabular}

(Reaction conditions: furfural $=5 \mathrm{~g}, 2$-propanol solvent $=100 \mathrm{~g}$, catalyst $=100-300 \mathrm{mg}$, reaction temperature $=250^{\circ} \mathrm{C}, \mathrm{H}_{2}$ pressure $=6.9 \mathrm{bar}$, stirring speed $=600 \mathrm{rpm}$ ). 
Figure 1. (a) HAADF-STEM image of Ni@Pt, and (b) EDX elemental mapping of the Ni@Pt marked in (a).
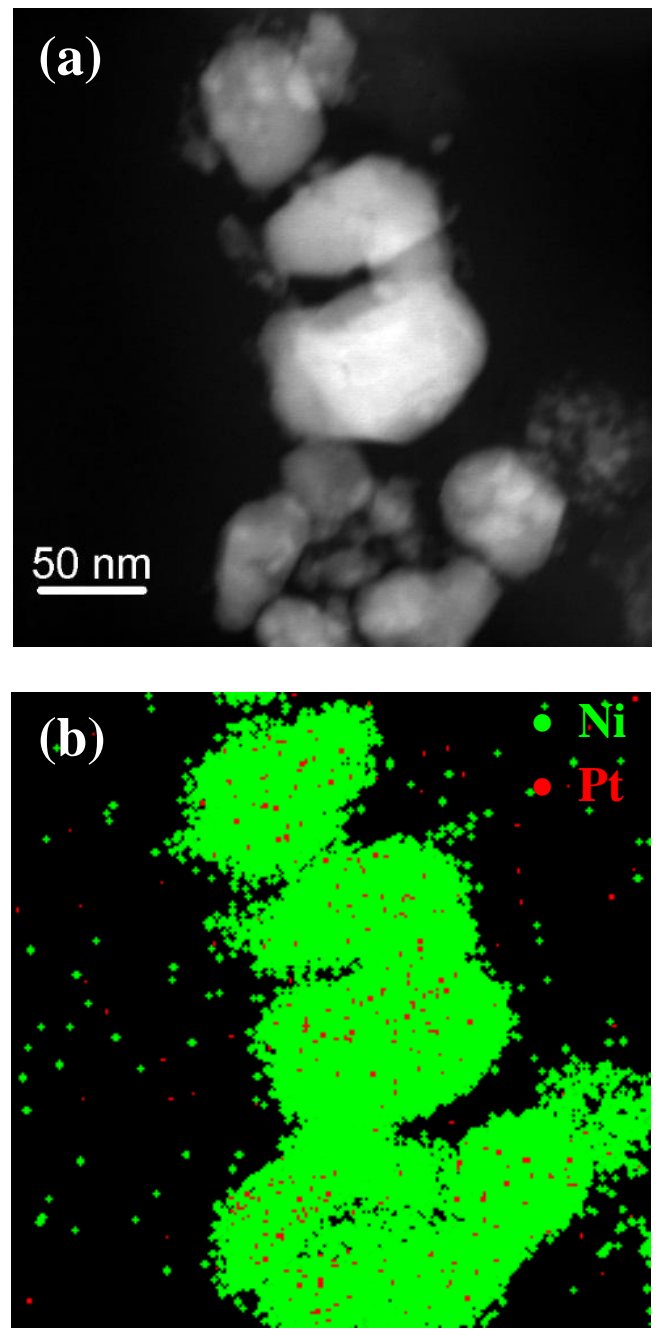
Figure 2. Correlation between furfural conversion TOF of surface Pt sites and heats of $\mathrm{H}_{2}$ adsorption for studied platinum overlayer catalysts and pure $\mathrm{Pt}$.

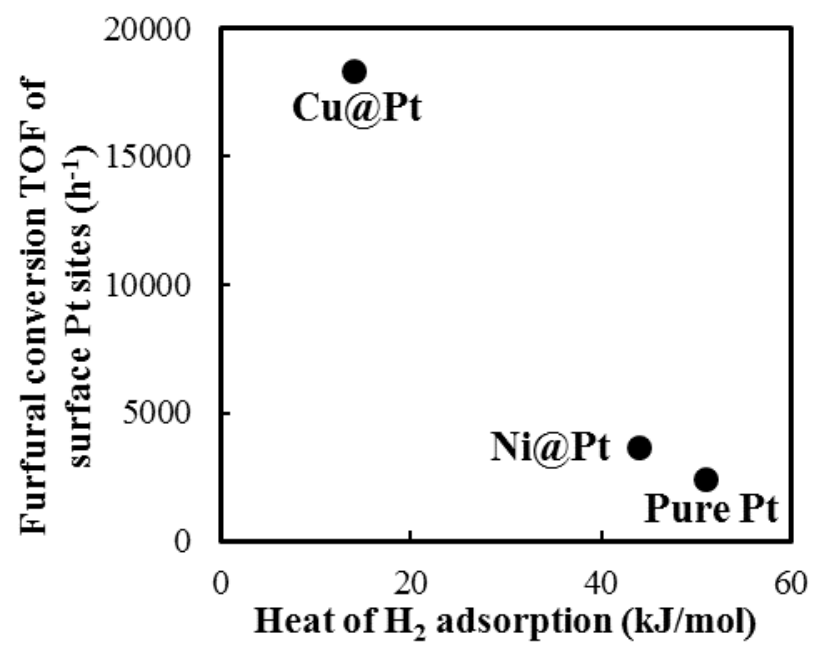


Figure 3. Selectivity toward furfuryl alcohol in furfural hydrogenation.

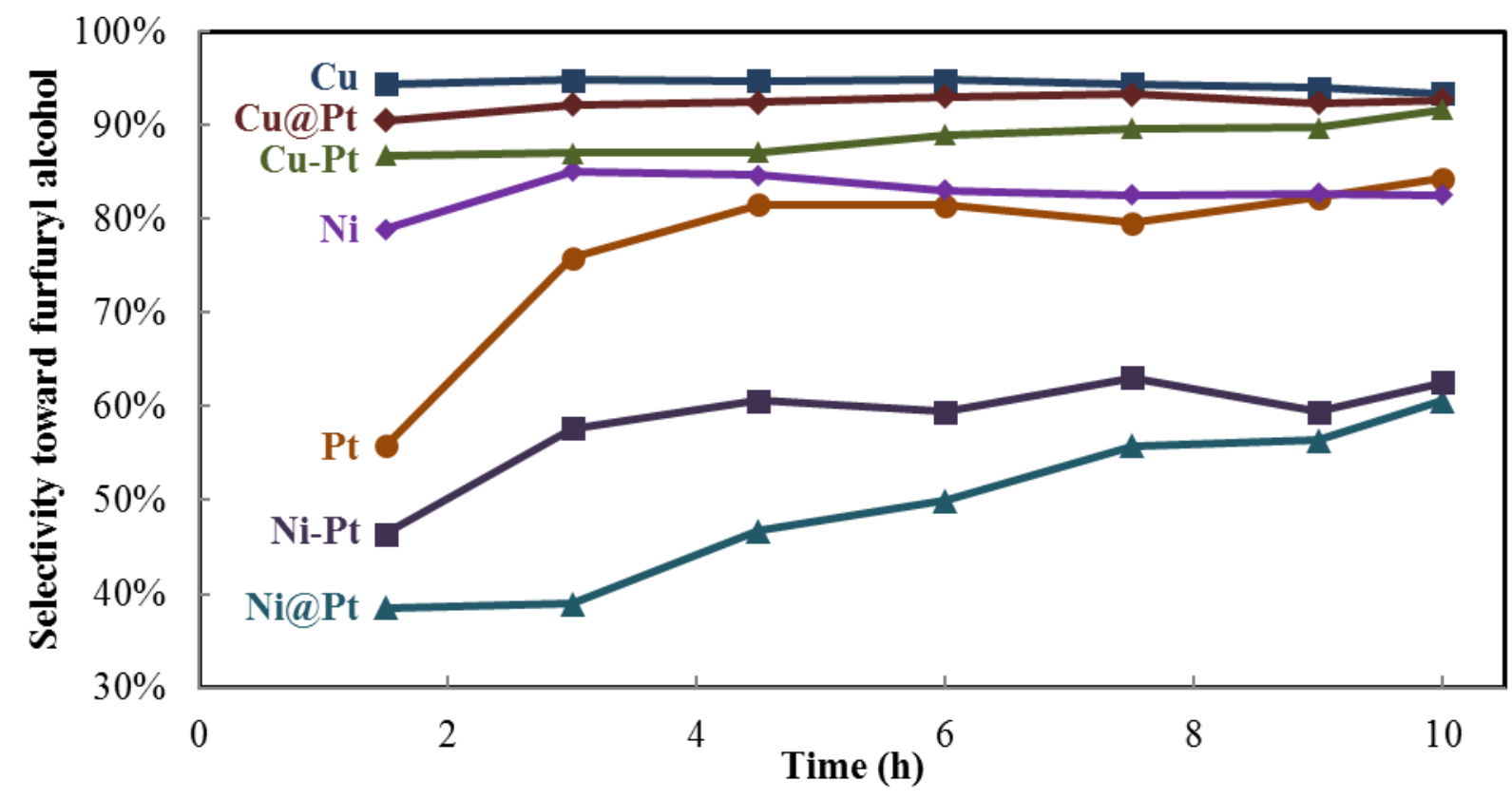

